\title{
Serviço de expansão da triticultura: política quantitativa, transformações qualitativas no agronegócio da mesorregião Noroeste RS - 1940/1955
}

\author{
Clovis Tadeu Alves*
}

\begin{abstract}
Resumo
Este artigo descreve o início da especialização produtiva agrícola na mesorregião Noroeste do Rio Grande do Sul, com a criação do Serviço de Expansão da Triticultura. Pretende identificar como um conjunto de medidas quantitativas geraram profundas transformações qualitativas na agricultura mesorregional, servindo de exemplo para a futura consolidação do moderno agronegócio brasileiro. Esse serviço proporcionou de forma pioneira a estrutura necessária para a produção de larga escala do trigo; induziu a formação de um ponto de inflexão na agricultura brasileira, pois pela primeira vez se produzia em larga escala no país outra cultura, além das tradicionais, café e cana-de-açúcar.
\end{abstract}

Palavras-chave: Serviço de expansão da triticultura. Modernização agrícola. Mesorregião Noroeste.

Bacharel em Ciências Econômicas UPF, Meste em História pelo PPGH da UPF - Universidade de Passo Fundo/RS. E-mail: clovis21@ibest.com.br 


\section{Introdução}

A criação do agronegócio brasileiro, principalmente as atividades relacionadas à produção de cereais e oleaginosas devem grande parte do seu sucesso a uma região produtiva do Rio Grande do Sul. Foi na mesorregião Noroeste gaúcha que, no início do Século XX, teve início um processo de modernização agrícola que se tornou um ponto de inflexão na agricultura brasileira. $O$ fato é que o processo de modernização e de criação do agronegócio na mesorregião Noroeste do Rio Grande do Sul, normalmente está relacionado com a implantação da Revolução Verde no Brasil, na década de 1960. Afirma-se que a Revolução Verde introduziu tecnologia de forma exógena na agricultura brasileira, auxiliando na resolução de uma complicada equação para o país, destravando o fornecimento de matéria-prima para a indústria em expansão, junto com o fornecimento de gêneros alimentícios para um país cada vez mais urbano.

Um fato até então pouco notável sobre a Revolução Verde é que essa utilizou uma estrutura agrícola, anterior, pré-existente, principalmente na mesorregião Noroeste do Rio Grande do Sul. Este trabalho centra-se justamente na formação dessa estrutura. Autores, como Brum ${ }^{1}$ (1983), Rückert ${ }^{2}$ (2003), Albuquerque e Silva $^{3}$ (2008), são unânimes em afirmar que a modernização da agricultura brasileira teve início no Planalto Médio gaúcho ainda na década de 1940 com o trigo. Observando as opiniões desses autores, e no intuito de especificar a região onde o processo ocorreu, bem como melhor delimitar geograficamente a região estudada, definiu-se por utilizar a mesorregião Noroeste do Rio Grande do Sul.

Essa, em destaque na Figura 1, compreende, além do Planalto Médio, a região do Alto Uruguai, parte da região Centro-Serra, a região do Médio Alto Uruguai, as Missões e o Noroeste Colonial. É formada pelas microrregiões de Carazinho, Cerro Largo, Cruz Alta, Erechim, Frederico Westphalen, Ijuí, Passo Fundo, Sananduva, Santa Rosa, Santo Ângelo, Soledade e Três Passos. Segundo os dados do IBGE (2010), a mesorregião Noroeste possui uma área de $64.942,00 \mathrm{~km}^{2}$, representando $24,16 \%$ do território do estado. Possui uma população, conforme o IBGE (2010), de 1.946.510 pessoas, que representam $18,20 \%$ do contingente populacional do estado. Está dividida em 223 municípios, com um PIB de $\mathrm{R} \$ 20.634 .904 .250,00$ resultando num PIB per capita, de $\mathrm{R} \$ 10.161,91$, abrangendo a principal região produtiva do estado e transformando-se, a partir da década de 1950, numa das principais regiões de produção agrícola do país. 
Figura 1 - Mesorregião Noroeste do Rio Grande do Sul

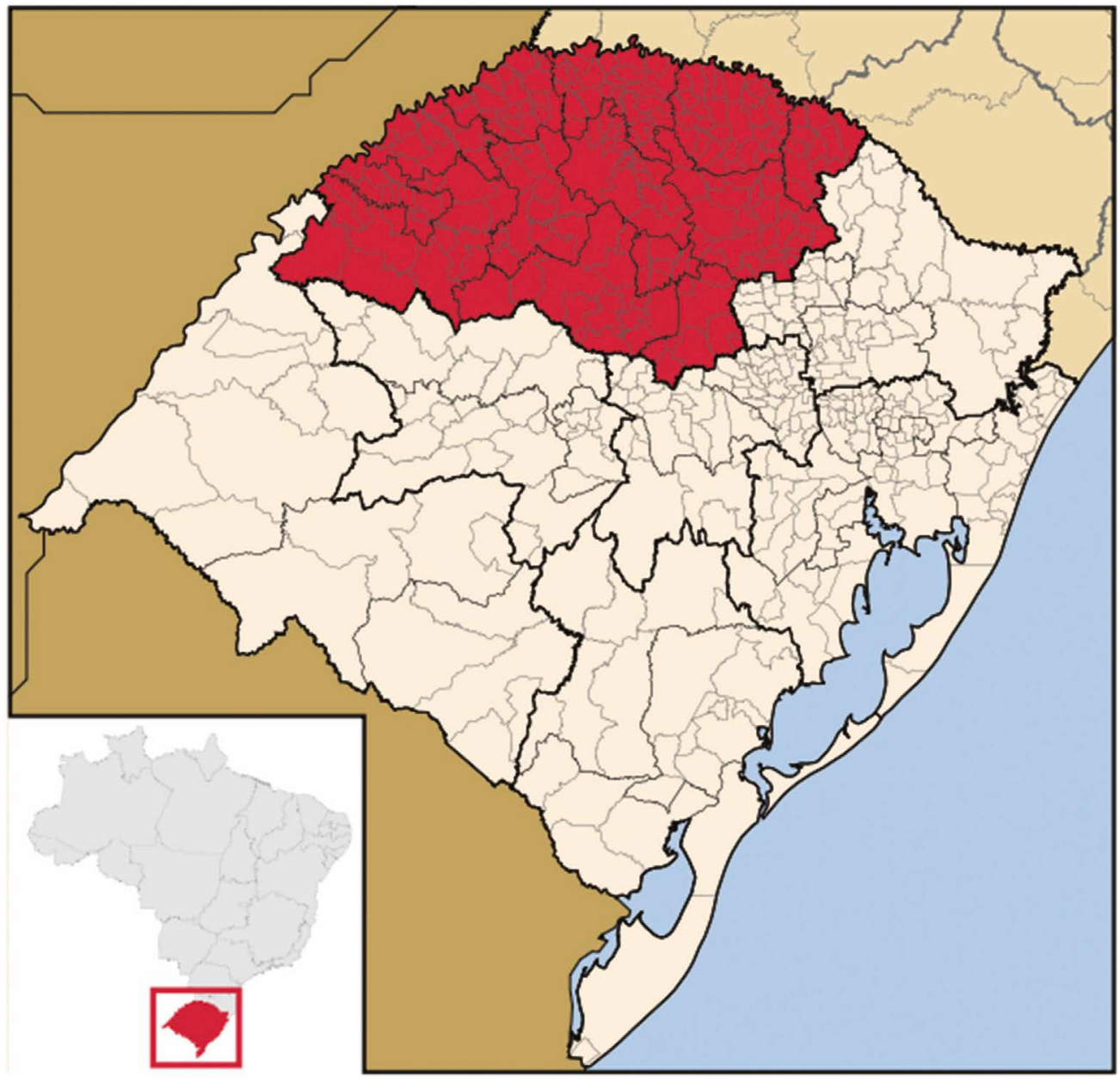

Fonte: http://pt.wikipedia.org/wiki/Ficheiro:RioGrandedoSul_Meso_NoroesteRioGrandense.svg.

A mesorregião, por ser pioneira, serviu de exemplo para a implantação de um modelo de desenvolvimento agrícola para outras regiões do país. Passou por um processo de modernização agrícola iniciado na década de 1930, impulsionado pelo direcionamento forçado da economia brasileira para a industrialização. ${ }^{4}$ Sua localização climática, inserida na região Sul do Brasil, única do país com clima temperado, ${ }^{5}$ possibilitou o desenvolvimento agrícola em larga escala, baseado nas cultivares oriundas desse clima, algo inédito na agricultura brasileira no início do Século XX. Essa região possui ainda uma grande área com relevo de planalto, com 
leves ondulações, ideais para a moderna prática agrícola, como uso intensivo da mecanização e de insumos modernos. Nesse sentido, em razão dos condicionantes naturais, ${ }^{6}$ impossibilitada de produzir em larga escala café e cana-de-açúcar, como o restante da agricultura "tropical" brasileira, no início do Século XX, a mesorregião apoiou-se nas culturas do trigo, do milho e, posteriormente, da soja para, assim, desenvolver sua agricultura. Nota-se que a região em estudo não possuía os condicionantes naturais para produzir as variedades da agricultura de clima tropical, mas possuía todos os condicionantes para produzir as cultivares da agricultura de clima temperado. Isso possibilitou o desenvolvimento agrícola de uma forma totalmente diferente do praticado no restante do país até então.

\section{O serviço de expansão da triticultura e as primeiras intervenções governamentais na agricultura mesorregional}

A necessidade de aumentar a oferta de alimentos na economia brasileira, a preferência do governo brasileiropara que parte ou a totalidade da produção fosse cultivada internamente, no que ficou conhecido como o processo de substituição das importações. Foram alguns dos fatores que desencadearam um processo nacional de modernização agrícola, substituidor de importação, que teve no Serviço de Extensão da Triticultura sua personagem principal. Nesse sentido, a mesorregião apresentava, na época, as melhores condições para o desenvolvimento da cultura do trigo no país. Percebendo isso, o governo passou a incentivar a sua produção em larga escala. $\mathrm{O}$ trigo foi o produto que destacou por primeiro a agricultura mesorregional, transformando-a numa espécie similar à da encontrada em países com clima temperado, como os Estados Unidos, possibilitando, assim, a acentuada transferência de tecnologia agrícola que iria se acentuar nas décadas de 1960 e 1970, com a Revolução Verde. Então, se pode afirmar que o aumento da produção de trigo, em nível nacional, estadual e mesorregional, foi a resposta a uma série de medidas governamentais de estímulo à produção. Para Silva (2001, p. 53), o início da "atividade tritícola teve como característica o desenvolvimento espontâneo da cultura, isto é, não incentivada pelo Estado, cabendo a este apenas a regulação do comércio exterior de cereais e armazenamento destes".

Apesar do desenvolvimento espontâneo inicial, o trigo teve incentivo estatal desde muito cedo no Rio Grande do Sul.Segundo Pesavento (1983, p. 172), os incentivos iniciaram-se na década de 1920, com o governo estadual de Getúlio Vargas. 
Ele passou a "exercer um controle sobre os preços, tabelando o preço do trigo tipo 'exportação' e comprando o que estivesse sem comprador". O governo tentava, com isso, aumentar as exportações do Estado e encontrar saídas para a zona rural além da pecuária (PESAVENTO, 1983). Quando Getúlio Vargas assumiu a presidência do Brasil passou a formular políticas nacionais de incentivo à cultura do trigo, já na década de 1930, com um projeto de industrialização do nacional desenvolvimentismo, iniciaram-se os projetos de apoio à cultura do trigo em nível nacional. A lei $\mathrm{n}^{0}$ 470, de 9 de agosto de 1937, trouxe incentivos importantes para a cultura, obrigando os moinhos no país a consumir pelo menos $5 \%$ do trigo nacional sobre o total do trigo estrangeiro. A lei, no seu artigo $6^{0}{ }^{7}$ ainda previa prêmios de estímulo direto aos produtores nacionais, como dinheiro por produtividade, fornecimento gratuito para o transporte de sementes nacionais; incentivos, como venda a preço de custo, parcelamento na aquisição de mecanização agrícola e descontos de $60 \%$ no transporte da produção. A lei previa ainda a instalação de moinhos pelo Ministério da Agricultura para atender à produção local onde os recursos particulares fossem escassos (BRASIL, 1937). Em 1938, a lei no 955, de 15 de dezembro de 1938, veio reafirmar o apoio governamental ao trigo. Essa pela primeira vez fixou um preço mínimo ao produto nacional, estabeleceu cotas proporcionais à capacidade de cada moinho para a aquisição do trigo nacional e constituiu pesadas multas aos moinhos transgressores, bem como o cancelamento do seu registro de comércio em caso de reincidência. Os estímulos governamentais, segundo a lei, eram justificáveis diante da necessidade de medidas que viessem assegurar a instalação e a fixação da produção nacional de trigo. A promoção de iniciativas que viessem beneficiar a balança econômica do país, substituindo e aliviando a necessidade de importação de trigo estrangeiro e, por fim indiscutível importância de promover sua produção com a fixação de um preço adequado (BRASIL, 1938).

Toda a estrutura montada para o incentivo da triticultura precisou ser revista com o fim da Segunda Guerra Mundial. Nesse momento, o governo brasileiro, ainda com Vargas, viu-se diante de um grande problema econômico agrícola: a demanda interna de trigo crescia e a oferta nacional do produto não conseguia acompanhá-la, criando, assim, uma nova dependência externa, a qual era agravada pela destruição, que a guerra proporcionara ao mundo: importantes áreas produtoras de trigo estavam destruídas na Europa e na Ásia, imaginava-se então que os estoques mundiais demorariam anos para se recuperar. Pensando em aumentar a produção nacional do produto e diminuir a dependência externa, Vargas criou o Serviço de Expansão da Triticultura com o decreto n⿳ำ 6.170, de 5 de janeiro de 1944, posteriormente revisado e ampliado (em 1946) pelo decreto $\mathrm{n}^{\circ} 20.507$, de 
24 de janeiro de 1946, sendo este diretamente subordinado ao Ministério da Agricultura. Teria por finalidade fomentar, orientar e controlar a produção, o comércio e a industrialização do trigo no país (BRASIL, 1946).

O Serviço de Expansão da Triticultura veio com um arcabouço mais estrutu$\operatorname{rado}^{8}$ e trouxe novas ferramentas para incentivar ainda mais a produção de trigo, além de reafirmar a fixação de um preço mínimo. O governo Vargas pretendia com isso incentivar a produção nacional do cereal, substituir a importação e concomitantemente iniciar um processo de inflexão na agricultura brasileira. A Figura 2 mostra como as medidas de incentivo do Serviço de Extensão da Triticultura possibilitaram o aumento da produção tritícola no país. Evidencia, ainda, dados produtivos da cultura, como a produção total de trigo, medida em toneladas, no Brasil e no Rio Grande do Sul, além de mostrar a área plantada no estado. O primeiro dado que se apresenta é o expressivo peso da produção estadual de trigo para o total da produção brasileira. No período, o estado produziu, em média, 74,78\% do trigo brasileiro. Observa-se ainda o expressivo aumento na área cultivada e na produção do produto. A área cultivada no Estado passou de 111.040 há, em 1931, para 982.484 há, em 1955, com um aumento na média da variação percentual em torno de $10,34 \%$ ao ano, significando uma alocação de área para a cultura de aproximadamente 36.310 ha por ano. A produção da lavoura, em 1931, era de 111.615 toneladas, com uma produtividade de 1,005 toneladas por hectare. Já em 1955, ápice na produção do produto, foi de 901.835 toneladas, com uma produtividade de 0,917 toneladas por hectare, o que se pode considerar um aumento na produção com perda de produtividade. Os dados indicam que houve uma expressiva alocação anual de área para o cultivo do produto, principalmente depois da criação do Serviço de Expansão da Triticultura, algo em torno de 36.310 ha/ano, a destinação maior de área coincidiu com a consolidação da colonização regional e a expansão agrícola dessa. 
Figura 2 - Trigo BR/RS

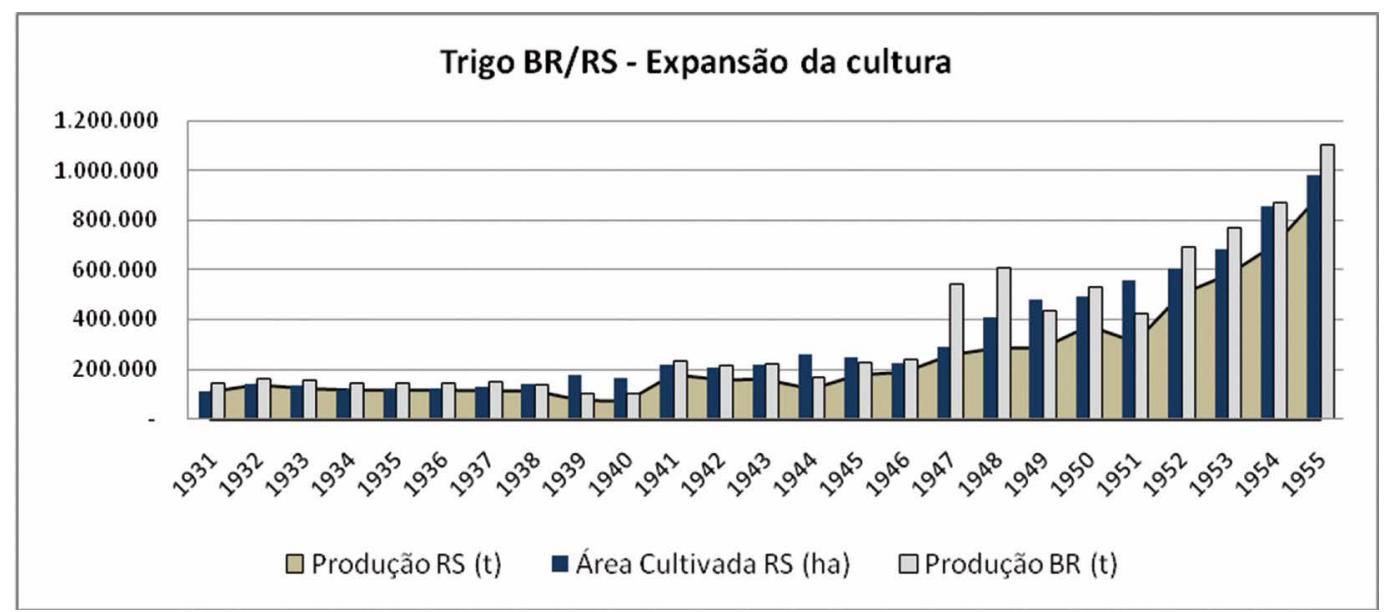

Fonte: http://www.ipeadata.gov.br/

De forma geral, as leis de incentivo ao trigo, até a metade da década de 1950, tiveram um impacto direto na agricultura da mesorregião Noroeste, isso se deu basicamente por dois motivos: primeiro pela condição climática da região Sul do Brasil, possuindo o clima mais adequado para o plantio de trigo no país (clima temperado) somando ao fato de ainda não existir tecnologia agrícola (principalmente sementes) para se plantar trigo no clima tropical brasileiro. O segundo motivo foi o contingente populacional existente, a população forma o que a geografia agrária chama de "condicionante humano", que está diretamente ligado ao desenvolvimento agrícola, fornecendo a força de trabalho, os recursos financeiros, bem como o sentido produtivo para a agricultura.

Foi no aspecto populacional que a região em análise levou vantagem em relação às demais regiões produtivas do sul do Brasil no início do século XX. O fator humano na região surgiu com a ocupação do seu território. Assim, apesar de ser a última região a ser colonizada no Estado, estava completamente ocupada no final da década de 1940. Coforme dados do Ipeadata.com, com bases no censo demográfico do IBGE na década de 1940, o Rio Grande do Sul possuía uma população de 3.320.689 pessoas, dessas 2.286.203 eram residentes no meio rural e 1.034.486, residentes no meio urbano. No mesmo censo, a população da mesorregião Noroeste era de 809.238 habitantes, que representavam $36,97 \%$ da população total residente do estado, desse total, 692.704 eram de população rural.

Um exemplo claro da importância do fator humano para a agricultura está na comparação do desenvolvimento agrícola da mesorregião Noroeste e da grande 
região Centro-Oeste paranaense (mesorregiões Noroeste, Oeste, Centro-Ocidental e Sudoeste paranaense). Essas duas regiões vieram rivalizar a partir da década de 1970 (já com a Revolução Verde) como grandes produtoras de tecnologia e na produção agrícola brasileira. De acordo com o censo de 1940, a grande região Centro-Oeste paranaense estava praticamente desabitada. Os dados demonstram apenas 7.645 habitantes em toda a grande região, devendo observar-se que na época a região era isolada e de difícil acesso. Entretanto, a mesorregião Noroeste, no mesmo censo, como já visto, possuía uma população de 809.238 habitantes, desse total $85,59 \%$ residiam ou dependiam de alguma forma do meio rural. Com uma grande população dependente do meio rural para sobreviver, a referida região detinha 0 condicionante humano, e foi capaz de desenvolver a agricultura já na década de 1940. Já a grande região Centro-Oeste paranaense, apesar de ter os condicionantes naturais (clima, solo etc.), não tinha população suficiente (condicionante humano) para desenvolver a agricultura nessa época. Dessa forma, entende-se porque motivo a agricultura se desenvolveu, primeiramente na mesorregião Noroeste, pois já dispunha de população para isso; ao contrário da grande região Centro-Oeste paranaense, que estava praticamente desabitada, demonstrando, com isso, a importância do equilíbrio entre os condicionantes no desenrolar do desenvolvimento agrícola.

Somando os dois fatores relacionados, é fácil observar que, apesar de as leis de incentivos à produção do trigo abrangerem todo o território nacional, foi na mesorregião Noroeste que ambas tiveram maior impacto e produziram os melhores resultados. Então pode-se afirmar que a lei era nacional, mas os impactos dos estímulos produtivos eram praticamente regionais. De acordo com os fatores supracitados, a lei seria para todas as regiões produtoras de trigo do país, mas a condição climática e a colonização delimitavam os incentivos produtivos para a mesorregião Noroeste do Rio Grande do Sul, praticamente a única produtora de trigo do país na primeira metade do século XX. Assim, não é exagero afirmar que os maiores beneficiados com as medidas de incentivo estatais eram os agricultores gaúchos, principalmente os produtores gaúchos da principal região produtora, a mesorregião Noroeste. 


\section{Transformação da estrutura agrícola mesorregional: dicotomia entre a agropecuária colonial e a agricultura empresarial}

O governo federal interviu na agricultura da mesorregião, principalmente a partir da implantação do Serviço de Expansão da Triticultura, quando se iniciou, então, um processo transformatório, originando uma dicotomia entre a agricultura praticada por agricultores já especializados, ou que estavam em via de especialização, e os produtores tradicionais. Nesse sentido, de acordo com Mueller (apud RAMOS; MORCELI, 2010, p. 2), as políticas agrícolas podem ser divididas em quantitativas e qualitativas. As quantitativas abrangem as políticas de estímulos, com a fixação de preço mínimo, subsídios, tributação diferenciada, seguro da produção, entre outras medidas; as qualitativas focam as mudanças estruturais, como o uso da terra, da infraestrutura e do desenvolvimento tecnológico. Observando a divisão proposta por Mueller, percebe-se que o governo atuou na primeira metade do século XX com políticas quantitativas, mas que geraram transformações qualitativas na agricultura mesorregional.

Nesse sentido, não se pode analisar as transformação ocorridas na agricultura mesorregional sem antes analisar alguns aspectos anteriores, ou seja, a base, o início, a estrutura. Para isso, devem-se observar as transformações ocorridas na agricultura antes do processo mutatório. A agricultura na mesorregião Noroeste surgiu como um desdobramento do processo de colonização ocorrido no início do século XX. Foi utilizada como um desafogo para o grande contingente de descendentes das populações migratórias do Estado, principalmente as oriundas das "colônias velhas". De início, os primeiros colonizadores da mesorregião, segundo Sponchiado (2000), podem ser chamados de "nacionais", entendidos como os colonos não imigrantes ou

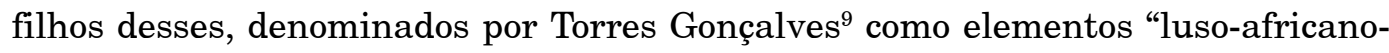
-brasileiros" (SPONCHIADO, 2000). Nota-se que esse primeiro grupo a se estabelecer na mesorregião Noroeste era de descendentes de portugueses, que constituíam os primeiros núcleos populacionais de Passo Fundo, Cruz Alta, Soledade, Carazinho, dentre outros. Com a chegada dos descendentes italianos e alemães, oriundos das "colônias velhas", à região de mata nativa no vale do rio Ijuí e a região do Alto Uruguai, fundaram as "colônias novas" de Guarani das Missões (1890), Panambi (1899), Erechim (1908), Santa Rosa (1915), dentre outras. Nesse estágio, embora continuassem a chegar imigrantes vindos da Europa, predominava a imigração 
interna, sobretudo pela escassez de terra e pelo excesso populacional nas "colônias velhas" (BRUM, 1988).

A ocupação do território por imigrantes procurando uma atividade que pudesse suprir suas necessidades capitalistas capaz de proporcionar uma melhora de vida era o elemento-chave ${ }^{10}$ da colonização mesorregional. Assim, o imigrante colonizador passou a reproduzir, na mesorregião, as atividades já predominantes nas "colônias velhas", a agricultura e a agropecuária de pequena escala. Portanto, a agricultura era a primeira e, muitas vezes, a única forma de o imigrante empreender, modificar sua estrutura social e conseguir seu objetivo. Para melhorar de vida era preciso trabalhar a terra, modificar o ambiente e adotar novas técnicas agrícolas. Então, à medida que se inseriam novas técnicas e novas tecnologias agrícolas, eram rapidamente adotadas pelos imigrantes para gerar mais excedentes e, assim, conseguir o seu intuito.

A colonização (fator humano) possibilitou o desenvolvimento da agricultura associada à pecuária de subsistência, que ficou conhecida como "agricultura colonial", ou "agropecuária colonial”. Para o produtor rural, na primeira metade do século XX era quase impossível investir só na agricultura, sem estar consorciado à pecuária, pois a agricultura ainda não era tão rentável e extremamente necessária para a criação de animais, como força de tração, renda, ou subsistência. Assim, falar de agricultura e agropecuária, contemporaneamente se referem a duas áreas bastante distintas, mas, na primeira metade do século XX, eram praticamente sinônimas, uma vez que era muito difícil para o produtor, em virtude da deficiência tecnológica, destinar toda a sua força produtiva na agricultura e deixar de lado a pecuária. Praticamente toda a produção agrícola da mesorregião (Tabela 2) vinha de estabelecimentos que praticavam a agropecuária de pequeno porte. Essa utilizava basicamente em seu sistema produtivo dois fatores de produção: a terra e o trabalho, bastante rudimentares em termos de técnica e na forma de produção, mas que atendiam praticamente a todas as necessidades de subsistência da população mesorregional.

A caracterização da agropecuária colonial "tradicional” foi estudada por Argemiro Jacob Brum em seu livro A modernização da agricultura: trigo e soja. O autor descreve que essa atividade se baseava na utilização intensiva da fertilidade natural do solo, e no uso da mão de obra da própria família do proprietário. O objetivo primeiro da produção era a alimentação da família, e o excedente, se existisse, era destinado à comercialização. Usavam-se instrumentos de trabalho simples e aplicados em pequenas propriedades (BRUM, 1988, p. 56). Segundo o estudo da Fundação de Economia e Estatística (FEE) (1978, p. 87), a agropecuária colonial 
era, na verdade, "a fronteira da capitalização, pois seus produtos são uma reserva de produção que está à espera de um novo lance da expansão produtiva". A agropecuária colonial caracterizava-se como um viveiro e depositário das experiências de cultivo agrícola gaúcho, pois se possibilitava a emergência de uma cultura para o aproveitamento empresarial. Também conservava a produção, quando a rentabilidade praticamente desaparecia, ou seja, a agropecuária colonial foi a que iniciou, praticamente, na tentativa e erro do plantio do trigo, do milho e da soja.

A Tabela 2 mostra a divisão da estrutura agrícola dos municípios que originalmente formavam a mesorregião Noroeste na década de 1940. É possível observar também o número de estabelecimentos subdivididos pelos respectivos setores produtivos: agricultura, agropecuária e pecuária. Os dados do censo agropecuário de 1940 revelam uma massiva concentração produtiva na agropecuária de pequena escala. Apesar de não ser explícito, subentende-se que a agropecuária constitui uma atividade de subsistência. Marcada pela presença do proprietário trabalhador detentor dos meios de produção, visando obter, no mínimo, a sua sobrevivência, utilizando, para isso, geralmente, terras de dimensões reduzidas e força de trabalho familiar (FEE, 1978, p. 95). Portanto, nesses aspectos, a agropecuária colonial representava, em termos percentuais, 90,82\% dos estabelecimentos produtivos mesorregionais. A especialização produtiva agrícola, ou seja, os estabelecimentos especializados somente em produzir gêneros agrícolas, principalmente grãos, sem a pecuária, somavam apenas $6,10 \%$ dos estabelecimentos recenseados. Deve-se ter em mente que o referido censo foi realizado no final da década de 1930 e ainda não refletia as profundas transformações que o Serviço de Expansão da Triticultura iria promover na mesorregião Noroeste. 
Tabela 2 - Evolução da estrutura agrícola na mesorregião Noroeste

\begin{tabular}{l|c|c|c|c|c|c}
\hline \multirow{2}{*}{\multicolumn{1}{c|}{ Municípios }} & \multicolumn{5}{c}{$\begin{array}{c}\text { Censo agrícola 1940 } \\
\end{array}$} & \multicolumn{2}{|c}{ Agricultura } & \multicolumn{2}{c}{ Agropecuária } & \multicolumn{2}{c}{ Pecuária } \\
\cline { 2 - 7 } & Gr. Escala & Peq. Escala & Gr. Escala & Peq. Escala & Gr. Escala & Peq. Escala \\
\cline { 2 - 7 } & 2 & 166 & 2 & 3886 & 86 & 20 \\
\hline Carazinho & 2 & 176 & 0 & 3608 & 211 & 55 \\
Cruz Alta & 0 & 248 & 0 & 7254 & 55 & 19 \\
Erechim & 0 & 236 & 0 & 2307 & 8 & 11 \\
Getulio Vargas & 2 & 155 & 3 & 4208 & 43 & 8 \\
ljuí & 0 & 79 & 0 & 1145 & 8 & 0 \\
Irai & 0 & 395 & 0 & 5340 & 189 & 237 \\
Lagoa Vermelha & 2 & 739 & 0 & 9104 & 131 & 12 \\
Palmeira das Missões & 0 & 576 & 1 & 4128 & 127 & 106 \\
Passo Fundo & 2 & 277 & 0 & 8583 & 28 & 13 \\
Santa Rosa & 1 & 838 & 0 & 6253 & 194 & 15 \\
Santo Ângelo & 4 & 89 & 0 & 2949 & 85 & 65 \\
Sarandi & 1 & 221 & 0 & 3708 & 179 & 189 \\
Soledade & 16 & 4195 & 6 & 62473 & 1344 & 750 \\
Mesorregião Noroeste* & 0 & & 0 & & & 0 \\
\hline
\end{tabular}

Fonte: IBGE, Censo Econômico do Rio Grande do Sul, de 1940.

* Foram selecionados os municípios que compreendiam a Mesorregião Noroeste em 1940.

À medida que as políticas agrícolas quantitativas do governo começavam a atuar no setor produtivo da região, iniciou-se uma separação mais acentuada entre a agricultura e a agropecuária; pois medidas do governo, como garantia de preço mínimo, prêmios em dinheiro, prêmios em máquinas, garantia de compra, possibilitaram que mais produtores se especializassem na agricultura como atividade produtiva, surgindo, assim, a agricultura empresarial. Esta pode ser definida como o segmento produtivo agrícola fortemente pautado por relações capitalistas. Que segundo FEE (1978, p. 88), caracteriza-se pela "continua valorização do capital para dar prosseguimento ao processo de acumulação, mediante a ampliação dos recursos técnicos [...] e do emprego de força de trabalho permanente e temporária, usando para a efetividade desta combinação terra própria ou arrendada". O comportamento da agricultura empresarial no Estado foi marcado por uma forte expansão, valendo-se de estímulos governamentais e de produzir produtos destinados ao abastecimento do mercado interno brasileiro, como o arroz na região Centro-Norte do Estado, e o trigo, na mesorregião Noroeste. 
Tabela 3 - Evolução da estrutura agrícola na mesorregião Noroeste

\begin{tabular}{|c|c|c|c|c|c|c|}
\hline \multirow{3}{*}{ Municípios } & \multicolumn{6}{|c|}{$\begin{array}{c}\text { Censo Agrícola } 1950 \\
\text { Em número de estabelecimentos }\end{array}$} \\
\hline & \multicolumn{2}{|c|}{ Agricultura } & \multicolumn{2}{|c|}{ Agropecuária } & \multicolumn{2}{|c|}{ Pecuária } \\
\hline & Gr. Escala & Peq. Escala & Gr. Escala & Peq. Escala & Gr. Escala & Peq. Escala \\
\hline Carazinho & 352 & 1292 & 98 & 1980 & 234 & 22 \\
\hline Cruz Alta & 236 & 1615 & 45 & 1973 & 236 & 78 \\
\hline Erechim & 396 & 6725 & 58 & 5438 & 272 & 49 \\
\hline Getulio Vargas & 129 & 1295 & 13 & 1199 & 42 & 17 \\
\hline ljuí & 488 & 1868 & 44 & 1951 & 81 & 18 \\
\hline Irai & 52 & 3216 & 8 & 1852 & 53 & 10 \\
\hline Lagoa Vermelha & 132 & 4381 & 19 & 2860 & 290 & 168 \\
\hline Marcelino Ramos* & 72 & 1552 & 8 & 1023 & 38 & 12 \\
\hline Palmeira das Missões & 231 & 6497 & 45 & 3149 & 228 & 86 \\
\hline Passo Fundo & 428 & 3469 & 52 & 2893 & 226 & 103 \\
\hline Santa Rosa & 255 & 8399 & 41 & 6445 & 331 & 2 \\
\hline Santo Ângelo & 298 & 4180 & 50 & 3096 & 340 & 89 \\
\hline Sarandi & 167 & 2930 & 53 & 3247 & 271 & 50 \\
\hline Soledade & 420 & 2990 & 93 & 2978 & 335 & 138 \\
\hline Três Passos* & 115 & 7820 & 23 & 3915 & 217 & 24 \\
\hline Mesorregião Noroeste** & 3771 & 58229 & 650 & 43999 & 3194 & 866 \\
\hline
\end{tabular}

Fonte: IBGE, Censo Econômico do Rio Grande do Sul, de 1950.

* Os municípios de Marcelino Ramos e Três Passos não existiam no censo de 1940.

** Foram selecionados os municípios que compreendiam a Mesorregião Noroeste em 1950.

Talvez a diferença marcante entre a agropecuária colonial e a agricultura empresarial, antes mesmo de seus métodos produtivos, seja o fundamento se sua existência. Enquanto que a agricultura empresarial tem como seu objetivo claro e lógico o lucro, para a agropecuária colonial esse não era o único fundamento, pois, de modo geral, seu objetivo principal era a subsistência do produtor e de sua família. No entanto, analisando os dados da Tabela 3, nota-se um aumento significativo de estabelecimentos especializados na agricultura. Isso se deu pelo fato de o trabalhador proprietário da agropecuária colonial antes de tudo ser um proprietário que percebe as nuanças de sua profissão e quer retirar o maior lucro possível do seu negócio. Assim, a partir do momento (principalmente com o surgimento do SET) que a agricultura começa a dar melhores resultados econômicos com o trigo, mais produtores abandonam a pecuária, ou passam a destinar mais recurso para a produção agrícola. Uma ação humana que a economia moderna chama de "custo de oportunidade", ou seja, para se produzir determinado produto, haverá de 
se renunciar a produção de outros, então se renuncia a produção de animais, por exemplo, para se ter uma melhor oportunidade econômica na produção tritícola.

Apesar de ter iniciado o plantio de trigo, a agropecuária colonial não se beneficiou tanto das ferramentas do Serviço de Expansão da Triticultura como a agricultura empresarial, uma vez que o objetivo principal desse era aumentar a produção do cereal; e a agricultura empresarial, que praticava a agricultura em larga escala, tinha melhores condições de atingir esse objetivo. A Tabela 3, com os dados referentes ao censo agropecuário do Rio Grande do Sul de 1950, mostra a evolução da agricultura empresarial em larga escala. Apesar de a agropecuária colonial ser bastante representativa, há um significativo aumento da atividade produtiva em larga escala na mesorregião. Decorrido apenas dez anos, a agropecuária colonial de pequena escala representa $39,74 \%$ do número de estabelecimentos, obtendo uma queda de $-51,08 \%$ em relação ao censo de 1940 . No Censo de 1950 a especialização agrícola, somando a agricultura de pequena e grande escala, chega a um montante de 55,99\% dos estabelecimentos, representando um impressionante aumento de $817,87 \%$ dos estabelecimentos destinados essencialmente à atividade agrícola. Então, um número significativo de estabelecimentos estava respondendo aos incentivos governamentais, iniciando a produção tritícola. O que é pouco observado é que o Serviço de Expansão da Triticultura criou uma estrutura "fictícia" de sustentação do produto, em que o governo intervinha diretamente no mercado, sustentando o preço e, consequentemente, a produção do trigo nacional. Embora muitos estabelecimentos estivessem migrando para a produção do cereal, ninguém sabia dizer na época o que aconteceria se o governo saísse do mercado.

A Figura 4 reflete a mudança no padrão produtivo da mesorregião Noroeste. Verifica-se um aumento de estabelecimentos produtivos destinados à agricultura (de 6,12\% no Censo de 1940 para 56\% no Censo de 1950) e uma importante diminuição nos destinados à agropecuária (de 90,83\% no Censo de 1940 para 40,33\% no Censo de 1950). O crescimento da agricultura se deu como um desdobramento dos estímulos governamentais para a cultura do trigo, mas representou também uma mudança estrutural no setor produtivo mesorregional. Com os estímulos à agricultura, tornou-se mais rentável e atraiu mais estabelecimentos agrícolas, de grande e pequeno porte, que conseguiam sobreviver só com a atividade agrícola, sem a necessidade de consorciamento com a pecuária. Isso, por si só, já é um indício da mecanização agrícola, pois o fato de serem estabelecimentos dedicados exclusivamente à agricultura indica o início da substituição da tração animal pela tração mecanizada. 
Figura 3 - Transformações nos estabelecimentos produtivos da mesorregião Noroeste do Rio Grande do Sul

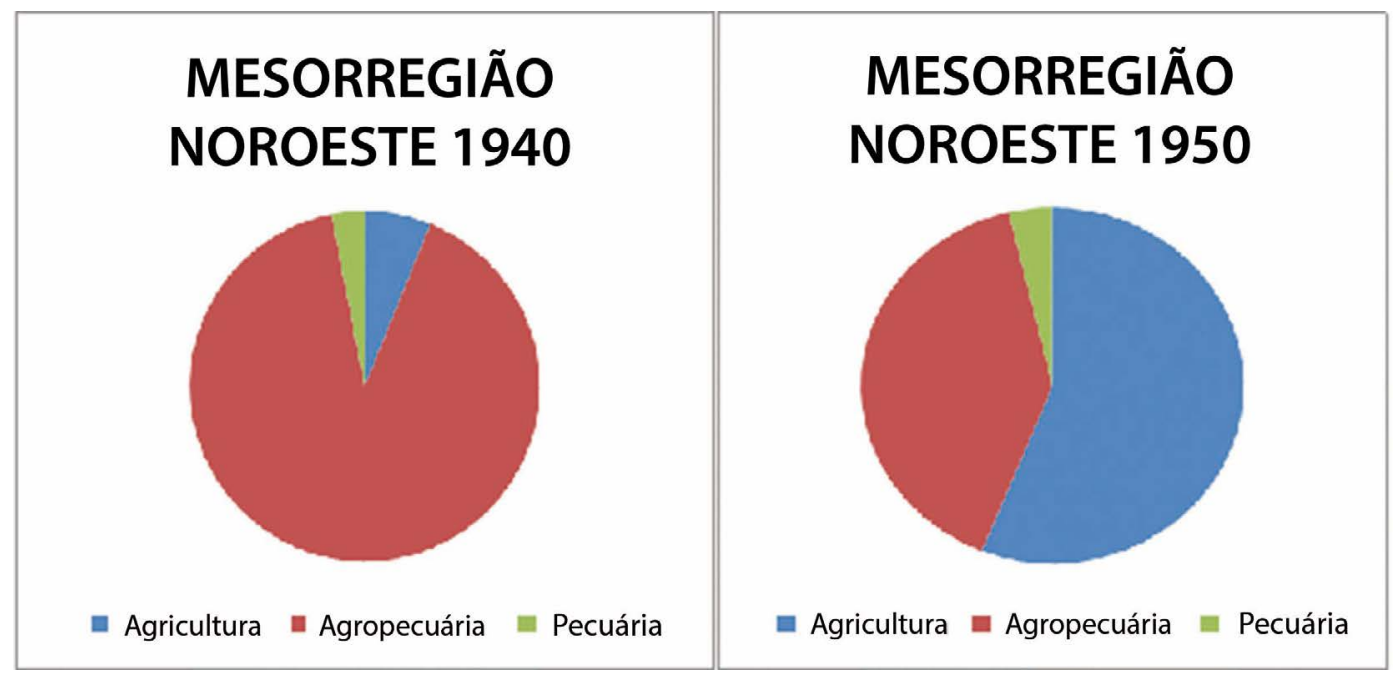

Fonte: IBGE, censo agropecuário do Rio Grande do Sul, 1940 e 1950.

Deve-se destacar o crescimento da agricultura de grande escala, passando de 16 estabelecimentos no censo de 1940 para 3.771 no censo de 1950. Esses estabelecimentos agrícolas especializados romperam as estruturas da agropecuária colonial e iniciaram a articulação com setores até então estranhos para a agricultura mesorregional, como o setor bancário, da indústria química e metal-mecânica. É nesse ponto que surge a dicotomia na atividade agrícola mesorregional, de um lado, a agropecuária colonial, de pequena escala, dedicada para a subsistência, representada pelo colono, de outro, a agricultura empresarial, dedicada à grande produção e ao lucro, representada pelo granjeiro.

\section{O serviço de expansão da triticultura e a modernização da estrutura agrícola mesorregional: granjeiros e cooperativas}

Terminada a década de 1940, a expansão da cultura tritícola na mesorregião Noroeste estava criando profundas transformações na estrutura agrícola, criando, assim, novas composições sociais e econômicas na sociedade mesorregional. Na década de 1950, a agricultura, então viável, era vista como uma forma de acumular capital. Para isso, foi necessária uma mudança na forma de produção, saindo da produção em pequena escala, de subsistência, para concentrar forças na produção 
em larga escala, empresarial, substituindo gradativamente as velhas tecnologias produtivas (tração animal, arado, fertilidade natural do solo etc.) e adotando novas tecnologias, geralmente importadas.

A nova realidade agrícola tornou a mecanização e a capitalização características comuns na agricultura mesorregional. A emergência capitalista na cultura do trigo introduziu nessa, além dos agricultores, os pequenos industriais, os comerciantes e os profissionais liberais, principalmente nos arredores dos centros urbanos mesorregionais, os quais adentraram no contexto como arrendatários de terra. Essa é uma questão quase lógica, pois, com o massivo incentivo governamental, a atração de pessoas mais acostumadas com negócios financeiros e que contaram com informação privilegiada, já que o dinheiro, os poderes e as diretrizes chegam, primeiramente, na cidade e posteriormente expandem-se para o interior. Nesse sentido, alguns estudos surgiram sobre a introdução de atores "estranhos" na agricultura regional. Caio Prado Jr (1976, p. 76-77) identifica que os estímulos das políticas oficiais de incentivos para a lavoura de trigo foram direcionados a grandes fazendeiros ou a pessoas completamente estranhas à agricultura, que, animados pelo lucro, entraram para esse novo negócio. Então, as políticas de incentivo foram mais bem aproveitadas por setores da sociedade que tinham mais facilidade com os negócios financeiros e maior representatividade nos mais diversos níveis do poder.

Em vista disso, Pebayle (apud RÜCKERT, 1974, p. 674-698), em trabalhos sobre a cultura do trigo na região do município de Passo Fundo, nas décadas de 1950 e 1960, classifica os agricultores, que adotaram a mecanização da lavoura de trigo, em dois subgrupos principais: a) os pioneiros inovadores, ou a primeira leva de adotantes, com área cultivada superior a $350 \mathrm{ha}$; b) os pequenos e médios produtores, ou a segunda leva de adotantes, com área de 150 a 350 ha. Denota-se um grande "peso" da grande propriedade no início da produção tritícola regional, assim surgiram novas classes no campo, um novo tipo de empresário (produtor de trigo com lavoura mecanizada) e um novo tipo de proletário (o tratorista, por exemplo) (FALKEMBACH, 1985, p. 142). Benetti (1992, p. 43) dá uma definição clara dos novos "empreendedores" rurais:

[...] os "granjeiros", "produtores rurais que se diferenciam dos "colonos" (pequenos produtores dentro de um sistema tradicional de cultivo) e dos "fazendeiros" e estancieiros (grandes proprietários dedicados a pecuária extensiva). Os granjeiros são os produtores que investem em máquinas equipamentos, utilizam trabalhadores assalariados e se dedicam ao cultivo especializado em grande escala e exclusivamente para o mercado. Eram antigos colonos ou seus descendentes que possuíam terra e complementarmente podiam exercer a atividade comercial e industrial (em pequena escala) de tal sorte que "puderam acumular recursos e experiência suficientes para aproveitarem as vantajosas possibilidades de obter lucros na produção de trigo em alta escala" (BENETTI, 1992, p. 43, grifo nosso). 
Os produtores conhecidos como "granjeiros" eram, em sua maioria, grandes proprietários. Segundo Rückert (2003, p. 50), eles já possuíam capitais acumulados previamente, como os comerciantes, industriais, profissionais liberais ou grandes proprietários de terras já estabelecidos. Rückert (2003, p. 50) caracteriza os granjeiros de trigo como a "fração da burguesia rural e urbana que, circunstancialmente, veem-se integrados numa mesma atividade produtiva, sem lastro histórico comum, mas deparando-se, a partir dum certo momento, com problemas comuns que os levam a definir um projeto político e a lutar por ele". Os esforços do governo em substituir as importações de trigo, implementando para isso um arcabouço de medidas quantitativas (Serviço de Expansão da Triticultura) acabara por criar uma nova classe rural, representada pelo grande produtor, o granjeiro. Assim, a criação dessa possibilitou a estruturação do agronegócio mesorregional criando as bases para o surgimento do complexo agroindustrial. Foram os esforços produtivos e de associativismo dos granjeiros (poder políticos e comercial), dos colonos (melhores oportunidades de negócios) e do governo (aumento da produção interna) que possibilitaram a formação das cooperativas tritícolas mesorregionais.

A união dessa nova classe rural, que contou com o incentivo do governo, possibilitou o início da organização de associações e sociedades rurais. Primeiramente, surgiram associações municipais, que se agruparam e formaram a Federação das Associações do Trigo (Featrigo) (RÜCKERT, 2003). Os problemas comuns de uma atividade tão imprevisível como a agricultura uniram os interesses de grandes produtores, os denominados granjeiros, e de um grande número de pequenos produtores, colonos. A partir do interesse mútuo, com a liderança dos granjeiros e com o apoio estatal, surgiram as cooperativas tritícolas na mesorregião, as quais estão intimamente relacionadas à incapacidade do governo federal de construir novos silos de armazenamento, responsabilidade que havia assumido. "Em 1956 o governo federal se convenceu de que não tinha condições de arcar com tal responsabilidade, preferindo devolvê-la aos próprios produtores, desde que se organizassem em cooperativas [...]" (BRUM, 1983, p. 128). Por esse motivo, ainda segundo Brum, a maioria das cooperativas tritícolas surgiu no ano de 1957.

O volume maior de produção concentrado em determinada época do ano (safra), sem a existência de estrutura para estocagem que possibilitasse ao produtor um melhor posicionamento na hora de vender o produto, justificava a formação das cooperativas, as quais, inicialmente, criaram a infraestrutura de armazenagem, mas, posteriormente, desenvolveram um complexo agroindustrial para processar a produção recebível (BRUM, 1983). Assim, o governo praticamente privatizou, ou melhor, "cooperativou" uma responsabilidade que ele próprio tinha assumido, levando os produtores a assumirem o ônus da intermediação pela construção de 
toda a infraestrutura de armazenagem e escoamento da produção. O Estado via na cooperativa um instrumento para atingir seus objetivos, apresentando-se como um protetor dos trabalhadores, adotando mecanismos de controle e de manipulação em relação às associações de trabalhadores e ao associativismo de setores produtivos (TEDESCO et al., 2005).

De fato, a cooperativa, ao concentrar a comercialização do cereal, reduzia relativamente os gastos de circulação da produção, tanto administrativos [...], quanto em investimento fixo [...]. Além disso, facilitava a compra estatal do grão, pois era muito mais fácil transacionar com as cooperativas do que a miríade de agricultores isolados. De outro lado, a concentração dos produtores facilitava a difusão de uma tecnologia de exploração dos solos mais avançada, capaz de aumentar a produtividade física e econômica da lavoura. Já que, à medida que a cooperativa permitia o repasse do crédito bancário oficial destinado à aquisição desses elementos materiais de produção, a cooperativa induzia a incorporação de tecnologia mais moderna por um maior número de produtores (TEDESCO et al., 2005, p. 139).

O direcionamento e o incentivo para a formação das cooperativas vieram, primeiramente, com o Serviço de Expansão da Triticultura de 1946, mas foi a partir de 1955 que importantes ações foram realizadas para aumentar a capacidade de armazenamento no país como um todo. Para tanto, foram tomadas várias medidas, como a criação da Comissão de Organização da Triticultura Nacional (Cotrin), pelo decreto $\mathrm{n}^{\circ} 41.490$, de 14 de maio de 1957, reformado pelo decreto $\mathrm{n}^{\circ} 43.191$, de 12 de fevereiro de 1958, que tinha como função dividir as regiões produtoras de trigo em zonas geoeconômicas; encorajar a constituição de uma cooperativa tritícola em cada zona; orientar e supervisionar as cooperativas criadas e promover a construção de silos e entrepostos (FRANTZ, 1982, p. 29). O cooperativismo foi um instrumento institucional utilizado pelo Estado para romper certas condições de atraso do desenvolvimento agrícola. As cooperativas eram o centro de um processo de fomento agropecuário onde fluíam todas as novidades que circundavam no meio agrícola e que o produtor esperava apoio técnico, comercial e político. Para Tedesco et al. (2005, p. 134), as cooperativas tinham o objetivo claro, além de substituir as atribuições de infraestrutura, de logística, de armazenagem, de assistência técnica e comercial, de amenizar conflitos sociais latentes no meio rural. Serviam também para substituir o próprio poder público, sem ônus para ele, na fiscalização do cumprimento de diversas leis e normas referentes ao trigo.

No que se refere à política nacional do trigo, a organização de cooperativas era interessante para o governo brasileiro em vista de sua política de substituição de importação, e, assim, consequentemente, induzir à expansão da triticultura nacional. De acordo com Benetti (1985), o ponto mais importante que devia ser salientado no processo de formação e desenvolvimento do cooperativismo gaúcho é que tanto formar quanto desenvolver s devem ser vistos como resultados da interação entre as políticas estatais de estímulo ao setor, os anseios, os esforços e a capacidade 
de auto-organização desses. "O que equivale a dizer que assim como sem o auxílio estatal o cooperativismo não prosperaria, também cairiam no vazio, as políticas de fomento, se não fosse a firme determinação dos produtores a defender organizadamente seus interesses" (BENETTI, 1985, p. 41). Benetti (1985) aborda muito bem o assunto, apesar da pressão e do incentivo estatal para a formulação de associações e cooperativas. Havia o grande e massivo interesse dos produtores rurais, representados principalmente pelos granjeiros na constituição dessas.

Com a divisão geoeconômica proposta por Cotrin surgiram dezenas de cooperativas na mesorregião Noroeste. Algumas figuram até os dias de hoje como importantes agentes do agronegócio mesorregional, outras sucumbiram por diversos motivos, o principal deles a má administração. Destacam-se algumas das cooperativas que atuaram, ou atuam, na mesorregião como a Coopasso (Passo Fundo), Cotrijuí (Ijuí), Cotrisal (Sarandi), Cotrigo (Getúlio Vargas), Camila (Lagoa Vermelha), Cotrijal (Não-Me-Toque), Cotripal (Panambi), Cotrisa (Santo Ângelo), Cotrel (Erechim), dentre outras. Com a união dessas e de outras cooperativas gaúchas surgiu, em 1958, a Federação das Cooperativas de Trigo (Fecotrigo), agregando, inicialmente, 29 cooperativas. Sua atividade era de cunho político e seu objetivo principal, era tutelar e representar suas filiadas perante os poderes político e público. Embora auxiliasse em todas as esferas econômicas da produção tritícola, havia no seu estatuto uma divisão do trabalho, em que às cooperativas associadas caberia a atividade econômica e à Fecotrigo, o apoio político e técnico (CALLAI, 2008).

\section{Considerações finais}

As ações governamentais que transformaram a agricultura na mesorregião Noroeste foram baseadas na pesada intervenção estatal, criando estruturas de mercado, praticamente insustentáveis em longo prazo. Essas estruturas, criadas a partir de políticas quantitativas, como a estratificação do mercado, a garantia de preço mínimo, a certeza de compra do trigo nacional, acabaram tendo profundo impacto na sociedade e no meio agrícola. Considerando o ritmo dessas transformações, imaginava-se um panorama favorável para a produção agrícola mesorregional, fato que não se confirmou, com a profunda crise na produção de trigo nacional na segunda metade da década de 1950 e na década de 1960. As explicações para a crise podem ser de cunho político e geopolítico e de cunho produtivo e de mercado.

Uma explicação de cunho político foi a ruptura que houve na política econômica nacional na década de 1950. Anteriormente, partiu de Vargas o desenvolvimentismo nacional populista, substituidor de importações, por meio da criação de empresas estatais, ou de capital brasileiro, substituído, por Juscelino, por um desenvolvimentismo com forte apoio do capital internacional. $\mathrm{O}$ reflexo desse 
direcionamento econômico foi sentido na agricultura mesorregional. Com a saída (morte) de Vargas do cenário político brasileiro, saiu também a defesa do trigo nacional, apesar de Juscelino ter mantido o Serviço de Expansão da Triticultura, esse não teve a mesma dinâmica na agricultura mesorregional. Na esfera geopolítica, destaca-se a nova política internacional do trigo, comandada pelos Estados Unidos, que por meio da Plublic Law 480 subsidiava a venda do seu excedente para países pobres, do assim chamado Terceiro Mundo, conhecida como: Acordos Internacionais do Trigo. No Brasil, de acordo com Silva (1992), o acordo previa inicialmente a compra de US\$ 31 milhões em trigo, que, posteriormente, foi estendido para US\$ 111 milhões, com pagamento em moeda nacional com prazo de quarenta anos. No âmbito de mercado, Ressalta-se o surgimento de graves fraudes na comercialização do trigo nacional, como o trigo papel, o passeio do trigo ${ }^{11} \mathrm{e}$ a nacionalização do trigo importado; constantes quebras de safra; excessiva regulamentação governamental; baixa relação preço-produtividade do trigo nacional.

O que é importante lembrar é que o Serviço de Expansão da Triticultura promoveu uma transformação agrícola na mesorregião Noroeste, tirando-a da predominância produtiva de subsistência, algo comum na agricultura brasileira (excluindo as grandes plantações de café e de cana-de-açúcar), para a agricultura de larga escala. Para alcançar esse novo status, os agricultores produtores tiveram que investir em tecnologia, a fim de poder cultivar uma área maior de terra. $\mathrm{E}$ foi exatamente essa tecnologia, esse potencial produtivo, que foi aproveitado para o início da produção em larga escala da soja. Então é perceptível que a mesorregião Noroeste detinha uma vantagem comparativa com relação a outras regiões produtoras do país no que tange ao início do cultivo da soja, pois tinha capital humano (agricultores) acostumado, familiarizado e interessado em novas técnicas e novas tecnologias agrícolas, que, sobretudo, acreditava e estava disposto a investir nelas.

Mas o que muitas vezes não é percebido é a importância do Serviço de Expansão da Triticultura no desenvolvimento do agronegócio brasileiro. Esse promoveu políticas quantitativas que geraram profundas mudanças qualitativas, criando a estrutura produtiva, a montante, com a indústria química e metal mecânica (contemporaneamente a mesorregião Noroeste tem um grande polo de máquinas agrícolas com tecnologia própria) e a jusante, com as cooperativas e as agroindústrias processadoras. Esse serviço foi o responsável pela disseminação da agricultura de larga escala, com variedades de clima temperado, algo essencial para o moderno agronegócio brasileiro e para a economia brasileira como um todo. Também, criou e transformou o capital humano que se tornou peça fundamental na disseminação da Revolução Verde, na década de 1960. Em última análise, criou o gaúcho agricultor, sojicultor, que levou o modelo primeiramente para o oeste paranaense, e posteriormente para o centro-oeste brasileiro, ocupando e desenvolvendo o interior continental do país. 


\title{
Service expansion wheatfield: quality policy quantitative transformation in agribusiness the Northwest mesoregion RS - 1940/1955
}

\begin{abstract}
The article goes back to the beginning of specialization in agricultural mesoregion Northwest Rio Grande do Sul, with the creation of the Service Expansion wheatfield. Aims to identify as a tangle of quantitative measures generated profound qualitative changes in the agriculture of the middle region, setting an example for the future consolidation of modern agribusiness. This service provided a pioneer structure needed for large scale production of wheat; induced the formation of a turning point in Brazilian agriculture, for the first time was produced on a large scale in the country another culture, beyond the traditional; coffee and cane sugar.
\end{abstract}

Keywords: Service Expansion Wheatfield. Agricultural Modernization. Mesoregion Northwest.

\section{Servicios de expansión del cultivo de trigo: políticas cuantitativas y cambios cualitativos en el agronegocio da la meso región Noroeste de RS - 1940/1955}

\section{Resumen}

El artículo describe el principio de la especialización productiva agrícola en meso noroeste de Río Grande do Sul, con la creación del Servicios de Expansión del Cultivo de Trigo. Tiene como objetivo identificar como un conjunto de medidas cuantitativas generó profundos cambios cualitativos en la agricultura mesorregional, un ejemplo para la futura consolidación de la agroindustria moderna. Siendo que este servicio prestado de forma pionera necesario para la producción de la estructura a gran escala del trigo; indujo la formación de un punto de inflexión en la agricultura brasileña, por primera vez, fue producido en gran escala en el país otra cultura, más allá de tradicional de café y caña de azúcar.

Palabras clave: Servicio trigal expansión. Modernización Agrícola. Mesorregião noroeste. 


\section{Notas}

1 O livro Modernização da agricultura no planalto gaúcho, de Argemiro Jacob Brum, trata da modernização agrícola na região.

2 O livro Metamorfoses do território: a agricultura de trigo/soja no Planalto Médio rio-grandense de 19301990, de Aldomar A. Rückert trata da modernização agrícola na região.

3 O livro Agricultura tropical: quatro décadas de inovações tecnológicas, institucionais e políticas, de Ana Cristina Albuquerque e Aliomar Gabriel da Silva, trata da expansão da agricultura de clima temperado no Brasil, um país tropical.

4 A industrialização do país aumentou a concentração nas cidades e, consequentemente, a demanda por alimentos, produtos em que a agricultura brasileira não conseguia produzir em larga escala até esse momento, em razão, sobretudo, de problemas tecnológicos e climáticos. Nesse ponto é que a agricultura da região Sul do país entrava com força, pois detinha os condicionantes agrícolas para a produção de larga escala de alimentos e uma população crescente com habilidade para isso.

5 Utilizando-se de critérios multidimensionais e de maior precisão, verifica-se que a área de clima tempe-

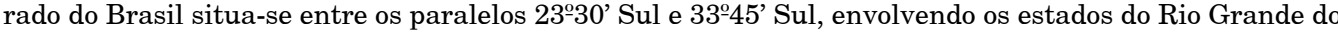
Sul, Santa Catarina e centro-sul do Paraná (EMBRAPA CLIMA TEMPERADO, 2000).

6 Geografia agrária denominada de fatores condicionantes para a agricultura, os fatores que condicionam a atividade agrícola numa determinada área. Existem dois tipos de condicionantes agrícolas: os naturais e os humanos. Os condicionantes naturais contribuem para facilitar ou dificultar a expansão da agricultura, sendo o clima, o relevo e os tipos de solo. Já o condicionante humano é essencial para a atividade agrícola, pois só o homem tem o poder de modificar os condicionantes naturais, desde que disponha de técnica e de capital para isso (ANDRADE, 1998). Os dois condicionantes juntos, apesar de parecerem simples, atuam de forma direta no desenvolvimento da agricultura.

7 Lei no 470, de 9 de agosto de 1937. Art. $6^{\circ}$ A título de estímulo e pelo prazo de cinco anos, fica instituído: um prêmio fixo, de dez mil réis por tonelada. A ser conferido ao lavrador que produzir um mínimo de mil quilos de trigo em grão, por hectare; um prêmio fixo, de quinze mil réis por tonelada, ao agricultor que produzir, em média, mais de mil e quinhentos quilos por hectare, numa área mínima de plantio de cem hectares; o fornecimento de requisição para transporte gratuito nas estradas de ferro e linhas de navegação para as sementes de trigo nacional, quando destinadas ao plantio; a venda aos agricultores ou grupo de lavradores, pelo preço do custo e a prestações, de maquinaria agrícola e moinhos de beneficiamento; um abatimento de sessenta por cento para transporte do trigo nacional sobre os fretes marítimos, fluviais, ferroviários e rodoviários das empresas oficiais de transporte, ou das empresas particulares que, em virtude de contrato com a administração pública, estejam obrigadas a atender a essa redução (BRASIL, lei no 470, de 9 de agosto de 1937).

8 Previa, dentre outras coisas: I) incrementar pela difusão do plantio, pelo ensaio cultural e pela melhoria dos métodos agrícolas a produção nacional de trigo; II) orientar e dar assistência técnica à lavoura tritícola nacional, promovendo a divulgação de métodos, processos racionais de cultura e beneficiamento do trigo, incentivando a prática da lavoura mecanizada; III) distribuir prêmios em dinheiro ou em material agrícola a critério do serviço aos lavradores que mais se distinguissem na produção de trigo; IV) promover por meio de revenda direta, a preço de custo, ou por empréstimo a curto prazo, o suprimento de máquinas agrícolas a triticultores registrados no Ministério da Agricultura; V) dar, quando se tratasse de pequenas áreas, ou revender a preço de custo adubos e corretivos aos triticultores registrados no Ministério; VI) cooperar no congregamento dos triticultores nacionais para a formação de cooperativas (BRASIL, dec. $\mathrm{n}^{\circ}$ 20.507, 24 jan. 1946).

9 Positivista gaúcho que comandou a direção da Diretoria de Terras e Colonização do Estado e participou ativamente da colonização da metade norte do estado (SPONCHIADO, 2000).

10 A associação do imigrante, do colono como o empreendedorismo, está em seu âmago. O agir capitalista muitas vezes exacerbado do imigrante, ora visto como "pão duro", ora como "louco por dinheiro", é abordado por Sombart, que, em sua análise, aborda, além das questões sociais, as questões econômicas, em que a figura do imigrante empreendedor é a figura central. O imigrante em sua nova sociedade não tem os freios morais da sociedade de onde saiu, está desfamiliarizado, rompeu as velhas tradições, enfim é um ser liberto para empreender, pois ganhar dinheiro e melhorar de vida foram os principais motivos que o fizeram imigrar (TEDESCO, 2010). Para Sombart, o ato de imigrar já é, em si, um ato empreendedor, um ato de ruptura, de esperança de mudar de vida. Essa expectativa de mudança cria no imigrante um agir capitalista muito exacerbado. Este é um elemento forte na constituição da sociedade regional, já que

Teoria e Evidência Econômica - Ano 20, n. 42, p. 67-90, jan./jun. 2014 
os imigrantes, que formaram a sociedade regional, tinham o pensamento de melhorar de vida, ganhar dinheiro, conquistar o seu espaço. Esse pensamento foi o propulsor do capitalismo moderno na região.

11 Passeio do trigo: saída de grãos de região produtora, onde havia moinhos, e transporte para o centro e norte do país. Criou-se, assim, a obrigatoriedade da aquisição e moagem da produção brasileira pelos pequenos moinhos situados nas respectivas regiões produtoras (ROSSI; NEVES, 2004, p. 68).

\section{Referências}

ALBUQUERQUE, Ana Christina Sagebin; SILVA, Aliomar Gabriel da. Agricultura tropical: quatro décadas de inovações tecnológicas, institucionais e políticas. Brasília: Ed. Embrapa, 2008.

ANDRADE, Manuel Correia de. Geografia econômica. 12. ed. São Paulo: Atlas, 1998.

BRASIL. Lei no 470, de 9 de Agosto de 1937. Disponível em: http://www2.camara.gov.br/legin/ fed/lei/1930-1939/lei-470-9-agosto-1937503404publicacaooriginal-1-pl.html. Acesso em: 15 jun. 2012.

BENETTI, Maria Domingues. Endividamento e crise no cooperativismo empresarial do Rio Grande do Sul: análise do caso Fecotrigo/Centralsul - 1975-83. Revista Ensaios FEE. Jul/Dez 1985, v. 6, n, 2, p. 23 - 55. Disponível em: http://revistas.fee.tche.br/index.php/ensaios/article/ view/934/1224. Acesso em: 15 jul. 2011.

BRASIL. Decreto-Lei no 955, de 15 de Dezembro de 1938. Disponível em: http://www2.camara.gov.br/legin/fed/declei/1930-1939/decreto-lei-955-15-dezembro-1938-349677-publicacaooriginal-1-pe.html. Acesso em: 15 jun. 2012.

. Decreto no. 20.507 - de 24 de Janeiro de 1946. Disponível em: <http://www6.senado.gov. br/legislacao/ListaPublicacoes.action?id=153367>. Acesso em: 15 jul. 2012.

BRUM, Argemiro Jacob. Modernização da agricultura no Planalto Gaúcho. Ijuí - Rio Grande do Sul: Fidene, 1983.

. Modernização da Agricultura trigo e soja. Petrópolis - RJ: Vozes, 1988.

CALLAI, Jaeme Luiz. Fecotrigo: um trabalho de união. Porto Alegre - RS: Sescoop, 2008.

EMBRAPA CLIMA TEMPERADO. II Plano Diretor: Embrapa Clima Temperado, 2000-2003. Pelotas, 2000. 34 p. (Embrapa Clima Temperado. Documentos, 72).

FEE. Fundaçao de Economia e Estatística: 25 anos de economia gaúcha. Volume 3. A agricultura do Rio Grande do Sul. Disponível em: <http:/www.fee.tche.br/sitefee/download/publicacoes/ digitalizacao/25-anos-economiagaucha/vol-3.pdf>. Acesso em: 15 ago. 2011.

FALKEMBACH, Elza M. F. Dinâmica social e cooperativismo: caso da Fecotrigo 1958/72. In: BENETTI, M. D. e FRANTZ, T. R. (Orgs.). Desenvolvimento e crise no cooperativismo empresarial do Rio Grande do Sul, 1957 / 1984. Porto Alegre: Fundação de Economia e Estatística, 1985.

FRANTZ, Telmo Rudi. Cooperativismo empresarial e desenvolvimento agrícola. Ijuí - RS: Fidene, 1982.

IPEADATA. Instituto de Pesquisa Economia Aplicada. Disponível em: http://www.ipeadata.gov. br/. Acesso em: 15 nov. 2011.

IBGE. Instituto Brasileiro de Geografia e Estatística: atlas das mesorregiões. Disponível em: http://200.198.213.88/spr/index.php. Acesso em: 15 ago. 2012. 
PESAVENTO, Sandra Jarahy. RS: agropecuária colonial e industrialização. Porto Alegre - RS: Mercado Aberto, 1983.

PRADO JR, Caio. História econômica do Brasil. 20. ed. São Paulo: Brasiliense, 1979.

RAMOS, Simone Yuri; MORCELI, Paulo. Conjuntura de mercado e intervenção governamental na agricultura: o caso da cadeia produtiva do arroz. In: CONGRESSO SOBER - Sociedade Brasileira de Economia Administração e Sociedade Rural, 48ㅜ, 2010, Campo Grande - MS, Artigo. p. 01-20. Disponível em: http://www.sober.org.br/palestra/15/594.pdf. Acesso em: 15 jun. 2012.

ROSSI, Ricardo Messias; NEVES, Marcos Fava. Estratégias para o trigo no Brasil. São Paulo: Atlas, 2004.

RÜCKERT, Aldomar A. Metamorfoses do território: a agricultura de trigo/soja no planalto médio rio-grandense 1930-1990. Porto Alegre, RS: Ed. UFRGS, 2003.

SILVA, Vera Martins da. A regulamentação do mercado do trigo. São Paulo: Ed. USP, 1992.

SILVA, Paulo Roberto Nunes da. Uma releitura do processo de transformações na agricultura gaúcha no período 1970-1980. Dissertação (Mestrado em Desenvolvimento Rural) Área de Concentração em Desenvolvimento Rural - Universidade Federal do Rio Grande do Sul, Porto Alegre, 2001. Disponível em: http://www.lume.ufrgs.br/bitstream/handle/10183/3388/000337349. pdf?sequence=1. Acesso em: 15 jun. 2012.

SPONCHIADO, Breno Antonio. O Positivismo e a colonização do norte do Rio Grande do Sul. Dissertação (Mestrado em História) Faculdade de Filosofia e Ciências Humanas - pontifícia Universidade Católica do Rio Grande do Sul - PUC/RS, Porto Alegre, 2000. Disponível em: http:// www1.capes.gov.br/teses/pt/2000_mest_pucrs_Breno_Antonio_Sponchiado.pdf. Acesso em: 15 fev. 2012.

TEDESCO, João Carlos; Estrangeiros, extracomunitários e transnacionais. Passo Fundo/Porto Alegre/Chapecó: Coedição Ed. UPF; PUC; Argos, 2010.

TEDESCO, João Carlos et al. Agroindústrias frigorificos e cooperativismo. Porto Alegre: Ed. Est, 2005. 